\title{
TEMPERATURA DO SOLO AFETADA PELA IRRIGAÇÃO E POR DIFERENTES COBERTURAS
}

Doi:http://dx.doi.org/10.1590/1809-4430-Eng.Agric.v35n5p817-828/2015

\section{GIOVANA G. RIBAS ${ }^{1}$, NEREU A. STRECK ${ }^{2}$, STEFANÍA D. DA SILVA ${ }^{3}$, THIAGO S. M. DA ROCHA ${ }^{4}$, JOSANA A. LANGNER ${ }^{5}$}

RESUMO: A irrigação suplementar e a cobertura do solo ("mulching") são práticas de manejo comumente usadas na agricultura. $\mathrm{O}$ objetivo deste trabalho foi quantificar a temperatura do solo desnudo com e sem irrigação, e sob diferentes coberturas do solo. Um ensaio de campo foi conduzido em Santa Maria-RS ( $29^{\circ} 43^{\prime}$ S latitude, 53 42' W longitude e $95 \mathrm{~m}$ de altitude), com seis diferentes áreas: solo desnudo sem e com irrigação, solo com "mulching" de plástico transparente (espessura $100 \mu \mathrm{m}$ ), "mulching" de plástico opaco preto (espessura $110 \mu \mathrm{m}$ ), "mulching" de plástico opaco branco (espessura $150 \mu \mathrm{m}$ ) e cobertura vegetal com palha na dose de $5 \mathrm{t} \mathrm{ha}^{-1}$. A temperatura do solo foi medida a $0,05 \mathrm{~m}$ de profundidade, diariamente, às $15 \mathrm{~h}$ (18 UTC), no período de 10-10-2011 a 31-05-2012. Foram também realizadas medidas horárias de temperatura do solo em quatro dias sem nebulosidade, em outubro e novembro de 2011, e janeiro e março de 2012. A temperatura do solo diurna seguiu a sequência: plástico transparente $\left(42,4{ }^{\circ} \mathrm{C}\right)>$ plástico opaco preto $\left(37,8{ }^{\circ} \mathrm{C}\right)>$ solo desnudo sem irrigação $\left(33,4{ }^{\circ} \mathrm{C}\right)>$ solo desnudo com irrigação $\left(29,2{ }^{\circ} \mathrm{C}\right)>$ palha $\left(27,0{ }^{\circ} \mathrm{C}\right)>$ plástico opaco branco $\left(24,6{ }^{\circ} \mathrm{C}\right)$. A região de Santa Maria-RS, tem potencial físico de aquecimento do solo com a técnica da solarização.

PALAVRAS-CHAVE: propriedades térmicas, "mulching", irrigação suplementar.

\section{EFFECT OF IRRIGATION AND MULCHING ON SOIL TEMPERATURE}

\begin{abstract}
Supplemental irrigation and mulching are management practices commonly used in agriculture. This study aimed to quantify soil temperatures in bare and covered soils with and without irrigation. The evaluations were carried out in Southern Brazil (Santa Maria-RS). The experimental area was divided into six treatments consisting of bare soil with irrigation, bare soil without irrigation, and soil-covered areas using transparent plastic mulch $(100 \mu \mathrm{m})$, black opaque plastic mulch $(110 \mu \mathrm{m})$, white opaque plastic mulch $(150 \mu \mathrm{m})$ and straw at a rate of $5 \mathrm{t} \mathrm{ha}^{-1}$. Soil temperature readings were taken once daily at $5 \mathrm{~cm}$ depth at $3 \mathrm{pm}$ (18 UTC) from October 10, 2011 to May 31, 2012. Moreover, hourly measurements were also made during four sunny days (cloudless sky) in October, November, January and March. Daytime soil temperature decreased as the following sequence: transparent plastic $\left(42.4{ }^{\circ} \mathrm{C}\right)$, black opaque plastic $\left(37 .{ }^{\circ} \mathrm{C}\right)$, bare soil without irrigation $\left(33.4{ }^{\circ} \mathrm{C}\right)$, bare soil with irrigation $\left(29.2^{\circ} \mathrm{C}\right)$, straw covering $\left(27.0^{\circ} \mathrm{C}\right)$ and white opaque plastic $\left(24.6{ }^{\circ} \mathrm{C}\right)$. Soil solarization is a potential mulching method to increase soil temperature in Santa Maria-RS, Brazil.
\end{abstract}

KEYWORDS: thermal properties, mulching, supplemental irrigation.

\footnotetext{
${ }^{1}$ Eng $^{\text {a }}$ Agronoma, Estudante de Mestrado pela Engo Agrícola/PPGEA, Departamento de Fitotecnia, UFSM/Santa Maria- RS, Fone: (55) 9962-2049, giovana.ghisleni@ hotmail.com

${ }^{2}$ Eng $^{\circ}$ Agronômo, Prof. Doutor, Departamento de Fitotecnia, UFSM/Santa Maria- RS, nstreck2@yahoo.com.br

${ }^{3}$ Meteorologista, Estudante de Doutorado pela Eng ${ }^{\circ}$ Agrícola/PPGEA, Departamento de Fitotecnia, UFSM/Santa Maria - RS, tefa.ds@hotmail.com

${ }^{4}$ Eng ${ }^{\text {O }}$ Agronômo, Estudante de Mestrado/PPGEA., Departamento de Fitotecnia, UFSM/Santa Maria- RS, thiagosmr@msn.com

${ }^{5}$ Eng $^{\mathrm{o}}$ Agronôma, Estudante de Doutorado pela Eng ${ }^{\circ}$ Agrícola/PPGEA ,Departamento de Fitotecnia, UFSM/Santa Maria -RS, langnerja@gmail.com 


\section{INTRODUÇÃO}

A temperatura do solo (TS) depende da radiação solar global incidente, das propriedades radiativas da superfície (absortividade e refletividade) e das propriedades térmicas do solo (calor específico, condutividade térmica e difusividade térmica) (STRECK et al., 1994). Para cada solo, as propriedades térmicas e radiativas dependem do conteúdo de água no solo. A TS afeta diretamente as plantas, pois desde a germinação da semente e após a emergência, a TS continua sendo importante, já que extremos de TS podem causar estresse térmico no tecido radicular, o que compromete a absorção de água e de nutrientes, o crescimento e a produtividade das culturas (GASPARIM et al., 2005).

A técnica de irrigação suplementar, além de fornecer água às plantas e aumentar a produtividade das culturas (FIGUEIREDO et al., 2008, ROSA et al., 2012), reduz o aquecimento diurno da superfície do solo desnudo pelo aumento do fluxo de calor latente na interface solo-atmosfera (LIAKATAS et al., 1986; PIRES et al., 2004). No solo desnudo com irrigação, ocorre menor temperatura máxima do solo devido à alta capacidade calorífera da água quando comparado ao solo desnudo sem irrigação (PIRES et al., 2004).

Outra maneira de reduzir as elevadas temperaturas diurnas do solo é através da cobertura do solo ou técnica do "mulching", que consiste na aplicação de uma cobertura na superfície do solo (LIKATAS et al., 1986; STRECK et al., 1994), sendo utilizada para diminuir a incidência de plantas daninhas e contribuir para a manutenção da temperatura e da umidade do solo (PIRES et al., 2004). As propriedades radiativas das diferentes coberturas determinam a disponibilidade de radiação solar global e a partição dos componentes do balanço de energia (calor no solo, calor latente e calor sensível) sob o "mulching", o que afeta a TS (STRECK et al., 1997). Há vários tipos de "mulchings", desde os naturais, como os resíduos das culturas, até os artificiais, como os filmes de plástico (CARVALHO et al., 2011; OLINIK et al., 2011; OLIVEIRA NETO et al., 2011).

Áreas de plantio direto são exemplos de uso de "mulching" natural, e o Brasil é uma referência mundial nesta técnica (BLAINSKI et al., 2012; FRANCHINI et al., 2012). A palha seca reduz a infestação por plantas daninhas (PERES et al., 2010; SUN et al., 2012; DING et al., 2013), além de reduzir a amplitude térmica diária pela diminuição da TS máxima e pela elevação da TS mínima diária (PEZZOPANE et al., 1996; GASPARIM et al., 2005).

O "mulching" com palhada favorece a infiltração da água no solo, reduz o escoamento superficial da água, do solo e dos nutrientes por erosão, aumentando a quantidade de matéria orgânica no solo, o que favorece a atividade microbiana e a reciclagem de resíduos orgânicos (CALEGARI, 2000; JORDÁN et al., 2010; ODHIAMBO \& IRMAK, 2012). Além destes benefícios, solos mantidos com cobertura morta apresentam conteúdo de água do solo maior do que solos sem cobertura morta, em função do aumento da capacidade de armazenamento de água (VAN DONK et al., 2010) e, também, devido às perdas de água por evaporação serem menores (SALTON \& MIELNICZUK, 1995; KNIES, 2010). Segundo ANDRADE et al. (2011), a evaporação do solo pode reduzir as perdas de água na camada até $0,1 \mathrm{~m}$ em 19 a 42\%, com 3 e $6 \mathrm{Mg} \mathrm{ha}^{-1}$ de palhada de aveia, comparado com o solo descoberto em novembro e dezembro de 2006, em Santa Maria-RS.

Os "mulching" plásticos são usados frequentemente em pequenas áreas com culturas olerícolas, sendo o filme de plástico opaco preto o mais usado. Um uso particular de "mulching" é na técnica da solarização, um método físico de desinfestação do solo (KATAN et al., 1976), que consiste na cobertura do solo úmido com plástico transparente. Esta técnica visa a aumentar a TS a níveis térmicos de inativação de patógenos, insetos e plantas daninhas (AMBROSIO et al., 2009; CONCEIÇÃO et al., 2009; SILVA et al., 2009; BASSETO et al., 2011; ZRIBI et al., 2011).

Em Santa Maria-RS, no interior de uma estufa de plástico, a TS diurna a $5 \mathrm{~cm}$ de profundidade foi menor sob plástico branco, seguido do amarelo e do verde, e maior sob plástico transparente, seguido do preto, do vermelho, do azul e do solo desnudo (STRECK et al., 1997). O potencial físico de aquecimento do solo pela solarização no interior de estufas de plástico, em Santa Maria-RS, foi determinado na década de 1990 (STRECK et al., 1996), com potencial de 
aquecimento de até $55^{\circ} \mathrm{C}$ nos meses de dezembro e janeiro, mas em campo este potencial ainda não foi quantificado.

O objetivo neste trabalho foi avaliar a temperatura do solo desnudo com e sem irrigação e sob diferentes coberturas de solo em diferentes estações do ano em ambiente subtropical.

\section{MATERIAL E MÉTODOS}

Este trabalho foi realizado no ano agrícola de 2011/2012, na área do Departamento de Fitotecnia da Universidade Federal de Santa Maria (29 $43^{\circ} \mathrm{S}, 53^{\circ} 42^{\prime} \mathrm{W}$ e $95 \mathrm{~m}$ ). O solo é uma transição entre a Unidade de Mapeamento São Pedro (Argissolo Vermelho distrófico arênico) e a Unidade de Mapeamento Santa Maria (Alissolo Hipocrômico Argilúvico Típico). Santa Maria está localizada na região fisiográfica da Depressão Central do Rio Grande do Sul, que, segundo a classificação de Köppen, apresenta clima Cfa (subtropical úmido sem estação seca definida e com verões quentes). O ensaio foi com: solo desnudo sem irrigação, solo desnudo com irrigação, solo coberto com "mulching" de plástico de polietileno transparente de baixa densidade (espessura 100 $\mu \mathrm{m}$ ), solo coberto com "mulching" de plástico opaco de polietileno preto (espessura $110 \mu \mathrm{m}$ ), solo coberto com "mulching" de plástico de polietileno dupla face, preto e prata (espessura $150 \mu \mathrm{m}$ ), solo coberto com "mulching" de palha na dose de $5 \mathrm{t} \mathrm{ha}^{-1}$. A face prata do "mulching" com plástico dupla face foi pintada com tinta comercial acetato polivinil de cor branca e voltada para cima, funcionando, portanto, como "mulching" opaco branco. Cada parcela tinha 3,5 $\mathrm{m} \mathrm{x} \mathrm{3,5} \mathrm{m}$ $\left(12,25 \mathrm{~m}^{2}\right)$, com espaçamento entre parcelas de $2 \mathrm{~m}$.

O ensaio iniciou-se em 10-10-2011 e terminou em 31-05-2012, e abrangeu as estações de primavera, verão e outono. A instalação das seis áreas no dia 10-10-2011 ocorreu pela manhã, quando o solo estava com umidade elevada após uma chuva de 30,6 mm, ocorrida em 08-10. Esta condição inicial de umidade do solo elevada foi imposta por uma chuva por ser um método fácil e barato para uniformizar a umidade do solo em todas as áreas no início do ensaio.

$\mathrm{Na}$ área de cobertura do solo com palha, usou-se, primeiramente, aveia-branca (Avena sativa) e, devido à decomposição da palha, no dia 22-12-2011, a palha de aveia foi substituída por palha de capim-sudão (Shorghum sudanense), uma gramínea de verão frequentemente usada como forrageira cultivada na região. Nos dias 03-02 e 06-03-2012 foram feitas substituições da palha de capim-sudão por nova palha desta mesma espécie, devido à alta taxa de decomposição durante os meses quentes.

$\mathrm{Na}$ área de solo desnudo com irrigação, a lâmina irrigada foi calculada com base na evaporação do tanque Classe "A" da Estação Climatológica do $8^{\circ}$ DISME/INMET, localizada a aproximadamente $100 \mathrm{~m}$ do local do ensaio. A equação utilizada foi:

$$
\mathrm{LI}=\mathrm{ETA} \times \mathrm{FC} \times \mathrm{A}
$$

em que,

LI - lâmina a irrigar (litros parcela $\left.{ }^{-1}\right)$;

ETA - evaporação do tanque Classe "A", das $9 \mathrm{~h}$ do dia anterior até às $9 \mathrm{~h}$ do dia $\left(\mathrm{mm} \mathrm{dia}^{-1}\right)$;

FC - fator de correção para levar em conta as diferentes resistências envolvidas na evaporação de água do solo desnudo, comparado com a evaporação de água do tanque classe "A", e

A - área da parcela $\left(12,25 \mathrm{~m}^{2}\right)$.

O FC foi 0,5 , ou seja, a evaporação do solo desnudo foi considerada $50 \%$ da evaporação do tanque Classe A, baseando-se na textura do solo a $10 \mathrm{~cm}$ de profundidade $(49,1 \%$ de areia, $32,43 \%$ de Silte e $18,47 \%$ de argila, classificado como solo franco) e observações visuais antes da instalação do ensaio (ensaio em branco) que indicaram ser um fator adequado para manter a camada superficial do solo úmida durante o período diurno. A irrigação foi feita com regador manual, entre 9 h e 30 min. e 10 h e 30 min, logo após a medida da ETA, às 9 h (12 UTC). Nos dias em que 
houve precipitação pluvial maior ou igual a $1 \mathrm{~mm}$, a irrigação foi suspensa e somente retomada 48 h após o último dia com chuva.

A temperatura do solo em cada área foi medida com um geotermômetro de mercúrio em vidro (elemento sensível - mercúrio), na profundidade de $0,05 \mathrm{~m}$, que é a profundidade de semeadura da maioria das culturas agrícolas e onde encontra-se uma boa parte da fauna edáfica. As observações foram feitas em todas as coberturas, diariamente, às $15 \mathrm{~h}$ (18 UTC), momento aproximado do dia em que ocorre a temperatura do solo máxima diária a 0,05 m neste local (STRECK et al., 1996).

Foram também realizadas medidas horárias de temperatura do solo a $0,05 \mathrm{~m}$ para caracterizar a onda diária de temperatura do solo em dias sem nebulosidade, ao longo do ensaio: das $6 \mathrm{~h}$ do dia 31-10-2011 até às $18 \mathrm{~h}$ do dia $1^{\mathrm{o}}-11-2011$, das $6 \mathrm{~h}$ do dia 25-11-2011 até às $11 \mathrm{~h}$ do dia 26-11-2011, das $5 \mathrm{~h}$ do dia 16-01-2012 até às $10 \mathrm{~h}$ do dia 17-01-2012 e das $5 \mathrm{~h}$ do dia 28-03-2012 até às $18 \mathrm{~h}$ do dia 29-03-2012. Estas datas representam dias típicos na primavera, verão e outono. Nestes dias de leituras horárias, a irrigação foi feita logo após as observações das $10 \mathrm{~h}$, de modo que, na observação das 11 h já se tinha o efeito da irrigação sobre os componentes do balanço de energia na superfície do solo. A lâmina irrigada nas áreas de solo desnudo, nestes dias de leituras horárias, foi 2,33 mm, 3,60 mm, 7,84 $\mathrm{mm}$ e $6,70 \mathrm{~mm}$, respectivamente.

As temperaturas mínimas e as máximas diárias do ar, a precipitação pluvial e a radiação solar global ao longo do ensaio foram medidas na estação meteorológica automática do $8^{0}$ DISME/INMET, localizada a aproximadamente $100 \mathrm{~m}$ do ensaio, e os gráficos de temperaturas mínimas e máximas diárias do ar, de precipitação pluvial e de radiação solar global foram plotados no software SigmaPlot, que é programa projetado para análise de dados científicos e gráficos.

\section{RESULTADOS E DISCUSSÃO}

As temperaturas do ar diárias, mínimas e máximas, ao longo dos 234 dias do ensaio variaram de 4 a $25,6^{\circ} \mathrm{C}$ e de 17 a $39^{\circ} \mathrm{C}$, respectivamente (Figura 1A). A densidade de fluxo de radiação solar global foi elevada durante os meses de verão, no período do ensaio, variando de 2,2 a $34,2 \mathrm{MJ} \mathrm{m}^{2} \operatorname{dia}^{-1}$ (Figura 1B). A precipitação pluvial de $802,7 \mathrm{~mm}$ foi abaixo da normal $(973,3$ $\mathrm{mm}$ ), assim como o número de dias com chuva (78 dias), durante os meses de outubro a abril, devido ao fenômeno La Niña. O mês de maio foi exceção devido a um evento isolado de 130,6 mm de chuva no dia 29-05-2012 (Figura 1B). Devido à baixa precipitação pluvial e ao baixo número de dias com chuva durante o período do ensaio, houve a necessidade de irrigação para manter a umidade elevada do solo na área de solo desnudo, com irrigação em 163 dias $(69,6 \%$ do total de dias do ensaio), o que totalizou $509,5 \mathrm{~mm}$ de água adicionada por irrigação complementar nesta área. 

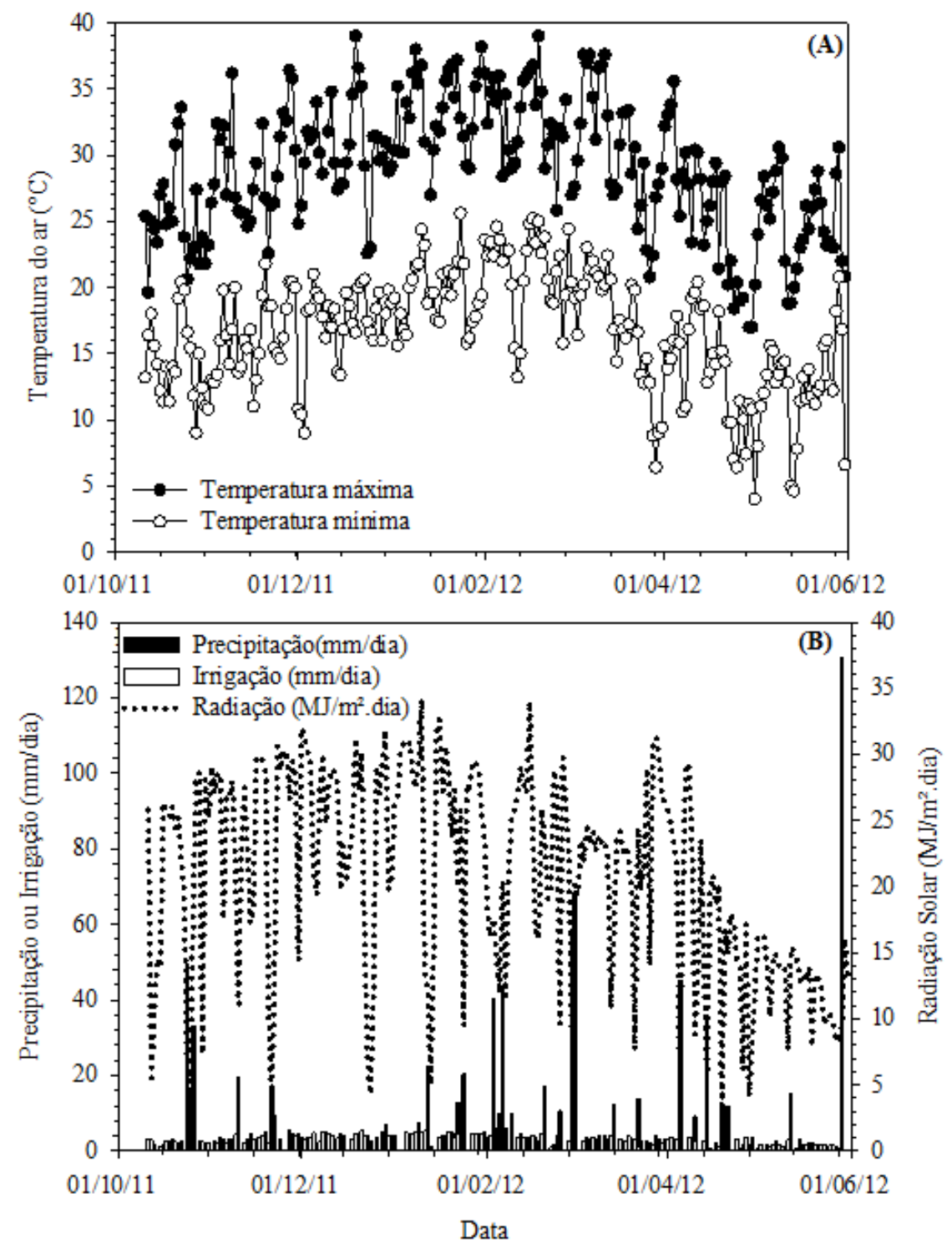

FIGURA 1. Temperatura do ar mínima e máxima diária (A), e precipitação pluvial, irrigação e densidade de fluxo de diária (B) ao longo do ensaio, Santa Maria-RS. Minimum and maximum daily air temperature $(A)$, rainfall, irrigation depth and solar radiation (B) throughout the experimental period in Santa Maria - RS, Brazil.

Os maiores valores medidos de temperatura do solo durante o ensaio, no solo desnudo sem irrigação, solo desnudo com irrigação, solo coberto com "mulching" plástico de polietileno transparente, "mulching" plástico opaco de polietileno preto, "mulching" opaco branco e solo coberto com palha, foram 49,$2 ; 39,4 ; 55,8 ; 54,6 ; 33,4$ e $36,6{ }^{\circ} \mathrm{C}$, respectivamente. Devido ao longo período do ensaio e à alta variabilidade dos dados diários de temperatura do solo, nas seis áreas, optou-se por apresentar as médias semanais de temperatura do solo ao longo do ensaio (Figura 2), pois a utilização de valores diários deixou os gráficos muito poluídos, dificultando a visualização e o entendimento. Em todas as semanas, a temperatura do solo seguiu a sequência: plástico transparente $\left(42,4{ }^{\circ} \mathrm{C}\right)>$ plástico opaco preto $\left(37,8{ }^{\circ} \mathrm{C}\right)>\operatorname{solo}$ desnudo sem irrigação $\left(33,4{ }^{\circ} \mathrm{C}\right)>$ solo desnudo com irrigação $\left(29,2{ }^{\circ} \mathrm{C}\right)>$ palha $\left(27,0{ }^{\circ} \mathrm{C}\right)>$ plástico opaco branco $\left(24,6{ }^{\circ} \mathrm{C}\right)$. Apenas em duas semanas (uma em novembro/2011 e uma em fevereiro/2012), a temperatura do solo com cobertura de palha foi superior $\left(1,12{ }^{\circ} \mathrm{C}\right.$ e $\left.1,35^{\circ} \mathrm{C}\right)$ à temperatura do solo desnudo com irrigação (Figura 2). Como o horário de observação da temperatura é próximo do horário de ocorrência da temperatura do solo máxima diária, a 0,02 m (STRECK et al., 1996), esta sequência representa o nível de aquecimento máximo em cada área. É notável, na Figura 2, a variabilidade intersemanal da 
temperatura do solo, associada à variabilidade de escala sinótica, principalmente devido a passagens regulares de frentes frias sobre o Rio Grande do Sul (CAVALCANTI \& KOUSKY, 2009). Além dessa, observou-se tendência parabólica das séries de temperatura do solo, com aumento do aquecimento a partir de novembro, máximo aquecimento em janeiro e fevereiro, e declínio a partir de março. Esta tendência estava em fase com a tendência parabólica da radiação solar global típica de região subtropical, durante a primavera, verão e outono.

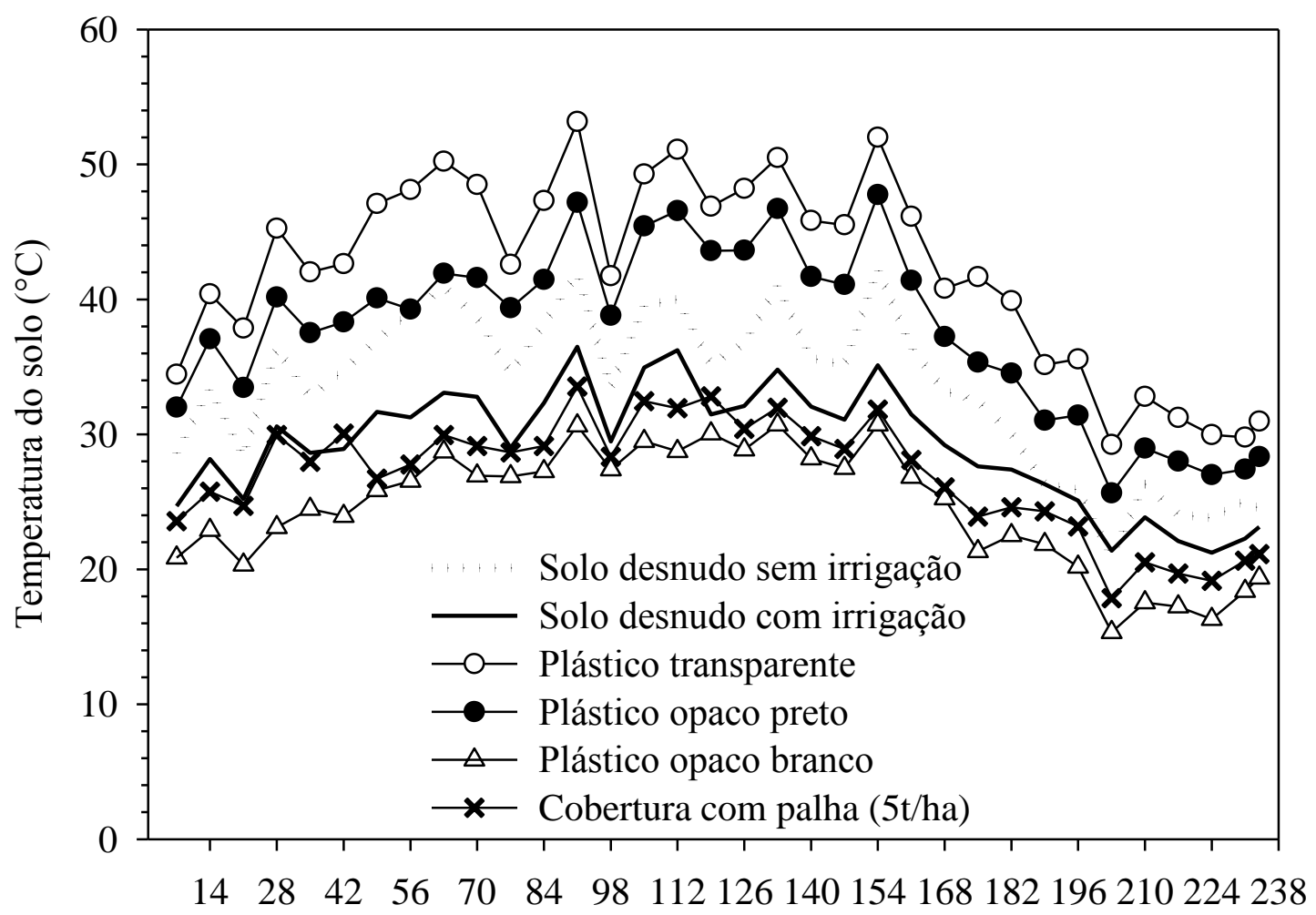

Dias

FIGURA 2. Temperatura do solo média semanal a $0,05 \mathrm{~m}$ de profundidade, às $15 \mathrm{~h}$ (18 UTC), no solo desnudo sem irrigação, solo desnudo com irrigação, solo coberto com plástico transparente, solo coberto com plástico opaco preto, solo coberto com plástico opaco branco e solo coberto com palha de aveia $\left(5 \mathrm{t} \mathrm{ha}^{-1}\right.$ ), de 10-10-2011 a 31-05-2012 (dias após o início do ensaio), em Santa Maria-RS. Weekly average soil temperature taken at $0.05 \mathrm{~m}$ depth at $3 \mathrm{pm}$ (18 UTC) in bare soils with and without irrigation, soils covered with transparent, black opaque, white opaque plastic mulches and straw covering $\left(5 \mathrm{tha}^{-1}\right)$. Readings were made from October 10 of 2011 to May 31 of 2012 in Santa Maria-RS, Brazil.

A variação diária de temperatura do solo a $0,05 \mathrm{~m}$ de profundidade no solo, nos quatro dias sem nebulosidade, é apresentada na Figura 3. As maiores temperaturas do solo ocorreram nos dias 26-11-2011 e 17-01-2012 (Figuras 3B e 3C), devido à maior disponibilidade de radiação solar global (30,2 e 27,2 $\mathrm{MJ} \mathrm{m}^{-2}$ dia $^{-1}$, respectivamente), comparado aos outros dois dias, 31-10-2011 e 29-03-2012 (Figuras 3A e 3D) (25,2 e 29,9 $\mathrm{MJ} \mathrm{m}^{-2}$ dia $^{-1}$, respectivamente). As curvas da variação horária da temperatura do solo são curvas típicas de ondas diárias de temperatura do solo em dias sem nebulosidade, em que a onda de calor segue a disponibilidade de radiação solar global ao longo do dia, e à noite o resfriamento do solo é função do balanço de ondas longas na superfície do solo. A única onda de calor que sofreu perturbação no período diurno foi a do solo com irrigação, onde é notável, nos quatro dias, que a elevação na temperatura do solo, nas duas áreas de solo desnudo, foi similar até às $10 \mathrm{~h}$ e a partir das $11 \mathrm{~h}$, quando havia sido realizada a irrigação na área com irrigação, a elevação na temperatura do solo desnudo sem irrigação ocorreu a taxas maiores do que no solo desnudo com irrigação. 



FIGURA 3. Variação horária de temperatura do solo a $0,05 \mathrm{~m}$ de profundidade, no solo desnudo sem irrigação, solo desnudo com irrigação, solo coberto com plástico transparente, solo coberto com plástico opaco preto, solo coberto com plástico opaco branco e solo coberto com palha de aveia $\left(5 \mathrm{t} \mathrm{ha}^{-1}\right)$ nos dias 31-10 a $1^{\mathrm{O}}-11-2011$ (A), 25 a 26-112011 (B), 16 a 17-01-2012 (C) e 28 a 29-03- -2012 (D), Santa Maria-RS. Hourly changes in soil temperature taken at $5 \mathrm{~cm}$ depth in bare soils with and without irrigation, soils covered with transparent, black opaque, white opaque plastic mulches and straw covering $\left(5 \mathrm{t} \mathrm{ha}^{-1}\right)$. Readings were made at varied periods: first from October 31 to November 1 of 2011 (A), secondly from November 25 to 26 of 2011 (B), thirdly from January 16 to 17 of 2012 (C) and finally from March 28 to 29 of 2012 (D) in Santa Maria-RS, Brazil.

Durante o período diurno, a sequência do aquecimento do solo, nos quatro dias típicos, foi a mesma da sequência da Figura 2. Durante o período noturno, no entanto, a sequência de temperatura mínima do solo foi: plástico transparente > plástico opaco preto > solo desnudo sem irrigação > palha > solo desnudo com irrigação > plástico opaco branco, ou seja, no solo com irrigação, o resfriamento noturno foi mais intenso que no solo coberto com palha. Era esperado que o nível de resfriamento noturno fosse maior no solo desnudo sem irrigação do que no solo desnudo com irrigação (STRECK et al., 1994). A possível explicação é que o intenso aquecimento no solo desnudo sem irrigação permite que o calor da camada superficial do solo seja transferido por condução para as camadas mais profundas. Ao realizar-se uma irrigação na camada superficial, será consumida mais energia para aquecê-la (devido ao maior calor específico volumétrico), resultando em menos energia térmica para aquecer as camadas mais profundas,

O efeito da irrigação no solo desnudo causou redução média na TS, às $15 \mathrm{~h}$, de $4,5{ }^{\circ} \mathrm{C}$, com maior redução nos dias em que houve irrigação $\left(6,5^{\circ} \mathrm{C}\right)$ do que nos dias em que não houve irrigação $\left(2,4{ }^{\circ} \mathrm{C}\right)$ (Tabela 1). Este resultado indicou que a irrigação suplementar forneceu água para maior consumo de calor latente e, assim, resultou em menor quantidade de energia térmica no solo. A diferença, embora menor, persistiu nos dias sem irrigação, possivelmente pelo acúmulo de energia térmica no solo sem irrigação ao longo do ensaio. Entre as coberturas com "mulching", a 
diferença de TS entre o plástico transparente e o plástico branco foi, em média, $20,4{ }^{\circ} \mathrm{C}$ e $16,8{ }^{\circ} \mathrm{C}$, e menor entre as demais áreas (Tabela 1). PIRES et al. (2004) relatam que a cobertura do solo e os níveis de irrigação têm influência na temperatura do solo máxima, tendo a irrigação causado redução de até $5,3{ }^{\circ} \mathrm{C}$ na temperatura do solo com utilização de plástico transparente no solo, em sistema de cultivo protegido.

Aspecto amplamente relatado na literatura e confirmado neste estudo, é a redução da amplitude térmica (diferença entre a máxima e a mínima) no solo sob palha, comparado com o solo desnudo (STRECK et al., 1994; PEZZOPANE et al., 1996), especialmente pela redução da temperatura máxima (Figura 3). Este aspecto é importante e benéfico por ocasião da semeadura de culturas de verão, como, por exemplo, a cultura da soja, cuja semeadura é realizada em novembro e dezembro no Rio Grande do Sul. Nos dias 25-11-2011 (Figura 3B) e 16-01-2012 (Figura 3C), a temperatura do solo a $0,05 \mathrm{~m}$ alcançou $35-37{ }^{\circ} \mathrm{C}$ e $40-42{ }^{\circ} \mathrm{C}$ no solo com e sem irrigação, respectivamente, enquanto no solo coberto com palha a temperatura alcançou $28-30{ }^{\circ} \mathrm{C}$ nestes dois dias. Para culturas de verão, como a soja, a faixa ótima de temperatura do solo adequada para a germinação das sementes é de 20 a $30{ }^{\circ} \mathrm{C}$ (FARIAS et al., 2009; SETIYONO et al., 2010), e temperaturas do solo acima de $42{ }^{\circ} \mathrm{C}$ reduzem a viabilidade das sementes de soja (LIMA et al., 2009; DODE et al., 2013) e de milho (ZUCARELI et al., 2011). Portanto, a manutenção de resíduos vegetais na superfície do solo tem papel importante no estabelecimento da cultura.

Com relação à TS entre as três coberturas com "mulching" de plástico (transparente, preto e branco), os resultados concordam com os obtidos por STRECK et al. (1996, 1997), em estufas de plástico na mesma região de estudo. A TS atingiu $55{ }^{\circ} \mathrm{C}$ em dois dias e foi maior que $50{ }^{\circ} \mathrm{C}$ em 44 dias, principalmente em dezembro, janeiro e fevereiro, o que indicou potencial físico do método da solarização nesta região, não apenas em estufa de plástico (STRECK et al., 1996; KLOCKE et al., 2009; ANDRADE et al., 2011), mas também em campo, já que temperaturas acima de $50{ }^{\circ} \mathrm{C}$ são letais a fungos patogênicos, insetos e sementes em germinação de plantas daninhas (KATAN et al., 1976; AMBROSIO et al., 2009; SILVA et al., 2009). Um indicativo do potencial da solarização observado durante o ensaio foi que, na parcela com plástico transparente, não houve crescimento de plantas daninhas, enquanto na área adjacente a esta parcela o nível de infestação por plantas daninhas foi elevado, o que exigiu capinas. Assim, o estudo do potencial de aquecimento do solo pela técnica da solarização aumentou o conhecimento a respeito desta técnica como mais uma alternativa de controle de patógenos, insetos e plantas daninhas no solo, para os agricultores de regiões subtropicais do Brasil. 
TABELA 1. Diferença média de temperatura do solo a $0,05 \mathrm{~m}$ de profundidade, às $15 \mathrm{~h}$ (18 UTC), entre as diferentes áreas, durante os meses de dezembro-2011, janeiro-2012 e fevereiro-2012, em dias em que foi feita irrigação e em dias em que não foi feita irrigação no solo desnudo. Lê-se a diferença entre as áreas citadas na vertical, menos as áreas citadas na horizontal. SDSI=solo desnudo sem irrigação, SDCI=solo desnudo com irrigação, $\mathrm{PT}=$ plástico transparente, $\mathrm{POP}=$ plástico opaco preto, $\mathrm{POB}=$ plástico opaco branco, Palha=cobertura de palha a 5 t/ha. Santa Maria-RS, 2011/2012. Average differences of soil temperature taken at $0.05 \mathrm{~m}$ depth at $3 \mathrm{pm}$ (18 UTC) among the evaluated areas in December of 2011, January of 2012 and February of 2012. The readings were taken from bare soils after irrigation and nonirrigated ones. The differences can be read between areas cited in vertical (columns) minus areas cited in horizontal (lines). SDSI = bare soil without irrigation, $\mathrm{SDCI}=$ bare soil with irrigation, $\quad \mathbf{P T}=$ transparent plastic, $\mathbf{P O P}=$ black opaque plastic, $P O B=$ white opaque plastic and Straw $=$ straw covering $(5 \mathrm{t}$ $\mathrm{ha}^{-1}$ ) in Santa Maria-RS, Brazil, in 2011 and in 2012.

\begin{tabular}{|c|c|c|c|c|c|}
\hline & SDCI & $\mathrm{PT}$ & POP & POB & Palha \\
\hline \multicolumn{6}{|c|}{ Dias com irrigação no SDCI (163 dias) } \\
\hline SDSI & 6,51 & $-9,29$ & $-4,06$ & 11,05 & 8,84 \\
\hline SDCI & & $-15,81$ & $-10,58$ & 4,53 & 2,32 \\
\hline PT & & & 5,23 & 20,35 & 18,13 \\
\hline POP & & & & 15,11 & 12,90 \\
\hline POB & & & & & $-2,21$ \\
\hline \multicolumn{6}{|c|}{ Dias sem irrigação no SDCI (71 dias) } \\
\hline SDSI & 2,41 & $-10,96$ & $-6,58$ & 5,83 & 4,63 \\
\hline SDCI & & $-13,37$ & $-8,99$ & 3,42 & 2,22 \\
\hline PT & & & 4,38 & 16,80 & 15,60 \\
\hline POP & & & & 12,41 & 11,21 \\
\hline POB & & & & & $-1,20$ \\
\hline
\end{tabular}

\section{CONCLUSÕES}

A irrigação é uma prática de manejo que altera o regime térmico do solo, com redução em média de $6{ }^{\circ} \mathrm{C}$ na temperatura máxima do solo, a $0,05 \mathrm{~m}$ de profundidade, comparado ao solo desnudo sem irrigação. Entre os "mulching", a maior temperatura do solo diurna ocorre sob cobertura de plástico transparente, enquanto o solo coberto com plástico opaco branco tem menor temperatura. A amplitude térmica diária do solo é menor no solo coberto com palha e com plástico opaco branco. A região de Santa Maria-RS, tem potencial físico de aquecimento do solo com a solarização. 


\section{REFERÊNCIAS}

ANDRADE, J.G.; SEGUÍ, J.P.; CARLESSO, R.; TROIS, C.; KNIES, A.E. Perdidas de agua por evaporacion em maiz con siembra convencional y directa para diferentes niveles de cobertura muerta. I. resultados experimentales. Revista Ciências Técnicas Agropecuárias, La Habana, v.20, p. 60-64, 2011.

AMBROSIO, M.M.Q.; BUENO, C.J.; PADOVANI, C.R. ; SOUZA, N.L. Sobrevivência de fungos fitopatogênicos habitantes do solo, em microcosmo, simulando solarização com prévia incorporação de materiais orgânicos. Summa Phypathologica, Botucatu, v. 35, n.1, p. 20-25, 2009.

BASSETO, M.A.; BUENO, C.J.; CHAGAS, H.A.; ROSA, D.D. ; PADOVANI, C.R. ; FURTADO, E.L. Efeitos da simulação da solarização do solo com materiais vegetais sobre o crescimento micelial de fungos fitopatogênicos habitantes do solo. Summa Phypathologica, Botucatu, v. 37, n.3, p. 116-120, 2011.

BLAINSKI, E.; TORMENA, C.A.; GUIMARÃES, R.M.L.; NANNI, M.R. Qualidade física de um latossolo sob plantio direto influenciada pela cobertura do solo. Revista Brasileira de Ciência do Solo, Viçosa, MG, v. 36, n.1, p. 79-87, 2012.

CALEGARI, A. Rotação de cultura. In: Guia para plantio direto. Ponta Grossa: Febrapdp, 2000. p. 68-78.

CARVALHO, D. F.; OLIVEIRA NETO, D.H.; RIBEIRO, R.L.D.; GUERRA, J.G.M.; ROUWS, J.R.C. Manejo da irrigação associada a coberturas mortas vegetais no cultivo orgânico da beterraba. Engenharia Agrícola, Jaboticabal, v. 31, n.2, p. 269-277, 2011.

CAVALCANTI, I.F.A.; KOUSKY, V.E. Frentes frias sobre o Brasil. In: IRACEMA FA CAVALCANTI, N.J.F.; SILVA, M.J.; DIAS, M.A.S. Tempo e clima no Brasil. São Paulo: Oficina de textos, 2009. p.135-147.

CONCEIÇÃO, M.A.F.; MARIN, F.R. Condições microclimáticas em um parreiral irrigado coberto com tela plástica. Revista Brasileira de Fruticultura, Jaboticabal, v. 31, n.2, p. 423-431, 2009.

DODE, J. de S.; MENEGHELLO, G.E.; TIMM, F.C.; MORAES, D.M.; PESKE, S.T. Teste de respiração em sementes de soja para avaliação da qualidade fisiológica. Ciência Rural, Santa Maria, v.43, n.2, p. 193-198, 2013.

DING, R.; KANG, S.; LI, F.; ZHANG, Y.; TONG, L. Evapotranspiration measurement and estimation using modified Priestley-Taylor model in an irrigated maize field with mulching. Agricultural and Forest Meteorology, Amsterdam, v.168, p. 140-148, 2013.

FARIAS, J.R.B.; NEUMAIER, N.; NEPOMUCENO, A.L. Soja. In: MONTEIRO, J.E.B.A. (Org.). Agrometeorologia dos cultivos: o fator meteorológico na produção agrícola. Brasilia: INMET, 2009. p. 263-277.

FIGUEIREDO, M.G.D.; FRIZZONE, J.A.; PITELLI, M.M.; REZENDE, R. Lâmina ótima de irrigação para o feijoeiro considerando restrição de terra e aversão ao risco do produtor. Acta Scientiarum. Agronomy, Maringá, v. 30, n. 1, p. 81-87, 2008.

FRANCHINI, J.C.; DEBIASI, H.; BALBINOT JUNIOR, A.A.; TONON, B.C.; FARIAS, J.R.B.; OLIVEIRA, M.C.N.; TORRES, E. Evolution of crop yields in different tillage and cropping systems over two decades in Southern Brazil. Field Crops Research, Amsterdam, v. 137, p. 178-185, 2012.

GASPARIM, E.; RICIERI, R.P.; DALLACORT, R. Temperatura no perfil do solo utilizando duas densidades de cobertura e solo nu. Acta Scientiarum. Agronomy, Maringá, v. 27, p. 107-115, 2005.

JORDÁN, A.; ZAVALA, L.M.; GIL, J. Effects of mulching on soil physical properties and runoff under semi-arid conditions in Southern Spain. Catena, Amsterdam, v. 81, n. 1, p. 77-85, 2010. 
KATAN, J.; GREENBERGER, A.; ALON, H.; GRINSTEIN, A. Solar heating by polyethylene mulching for the control of diseases caused by soil-borne pathogens. Phythopathology, Saint Paul, v.66, p. 683-668, 1976.

KLOCKE, N.L.; CURRIE, R.S; AIKEN, R.M. Soil water evaporation and crop residues. Transactions of the ASABE, Saint Joseph, v.52, p. 103-110, 2009.

KNIES, A. E. Temperatura e umidade de um solo franco arenoso cultivado com milho. 2010. 104f. Dissertação (Mestrado em Ciência do Solo) - Universidade Federal de Santa Maria, Santa Maria, 2010.

LIAKATAS, A.; CLARK, J.A.; MONTEITH, J.L. Measurements of the heat balance under plastic mulches. Agricultural and Forest Meteorology, Amsterdam, v.36, n. 3, p.227-39, 1986.

LIMA, E.V., CRUSCIOL, C.A.C., CAVARIANI, C.; NAKAGAWA, J. Caracteristicas agronomicas, produtividade e qualidade fisiológica da soja "safrinha" sob semeadura direta, em função da cobertura vegetal e da calagem superficial. Revista Brasileira de Sementes, Viçosa, MG, v.31, p.69-80, 2009.

ODHIAMBO, L.O.; IRMAK, S. Evaluation of the impact of surface cover on single and dual crop coefficient for estimating soybean actual evaporation. Agricultural Water Management, Nebraska, v.104, p.221-234, 2012.

OLINIK, J.R.; OLIVEIRA JUNIOR, A.; KEPP, M.A.; REGHIN, M.Y. Produtividade de híbridos de abobrinha italiana cultivados com diferentes coberturas de solo. Horticultura Brasileira, Brasília, v. 29, p. 130-134, 2011.

OLIVEIRA NETO, D.H.; CARVALHO, D.F.; SILVA, L.D.B.; GUERRA, J.G.M.; CEDDIA, M.B. Evapotranspiração e coeficientes de cultivo da beterraba orgânica sob cobertura morta de leguminosa e gramínea. Horticultura Brasileira, Brasília, v. 29, p. 330-334, 2011.

PERES, J.G.; SOUZA, C.F.; LAVORENTI, N.A. Avaliação dos efeitos da cobertura de palha de cana-de-açúcar na umidade e na perda de água do solo. Engenharia Agrícola, Jaboticabal, v.30, p. 875-886, 2010.

PEZZOPANE, J.E.M.; CUNHA, G.M.; ARNSHOLZ, E.; COSTALONGA JÚNIOR, M. Temperatura do solo em função da cobertura morta por palha de café. Revista Brasileira de Agrometeorologia, Santa Maria, v. 4, n.2, p. 7-10, 1996.

PIRES, R.C.M.; FOLEGATTI, M.V.; JÚNIOR, M.J.P.; SAKAI, E.; PASSOS, F.A.; ARRUDA, F.B.; CALHEIROS, R.O. Efeito de níveis de água, coberturas do solo e condições ambientais na temperatura do solo e no cultivo de morangueiro em ambiente protegido e a céu aberto.

Engenharia Agrícola, Jaboticabal, v.24, n.3, p.663-674, 2004.

ROSA, R.D.; PAREDES, P.; RODRIGUES, G.C.; ALVES, I.; FERNANDO, R. M.; PEREIRA, L.S.; ALLEN, R.G. Implementing the dual crop coefficient approach in interactive software. 1. Background and Computing Strategy. Agricultural Water Management, Amsterdam, v.103, p. 8-24, 2012.

SALTON, J.C.; MIELNICZUK, J. Relações entre sistemas de preparo, temperatura e umidade de um Podzólico Vermelho-Escuro de Eldorado do Sul (RS). Revista Brasileira de Ciência do Solo, Viçosa, MG, v. 19, p. 313-319, 1995.

SETIYONO, T. D.; CASSMAN, K.G.; SPECHT, J.E.; DOBERMANN, A.; WEISS, A.; YANG, H.; CONLEY, S.P.; ROBINSON, A.P.; PEDERSEN, P.; De BRUIN, J.L. Simulation of soybean growth and yield in near-optimal growth conditions. Field Crops Research, Amsterdam, v.119, p.161-174, 2010.

SILVA, M.G.; OLIVEIRA, C.M.; JUNQUEIRA, A.M.R. Efeito da solarização e da adubação sobre artrópodes em solo cultivado com alface. Horticultura Brasileira, Brasília, v.27, p. 465-472, 2009.

STRECK, N.A., SCHNEIDER, F.M., BURIOL, G.A. Modificações físicas causadas pelo mulching. Revista Brasileira de Agrometeorologia, Santa Maria, v.2, p. 131-142, 1994. 
STRECK, N.A.; SCHNEIDER, F.M.; BURIOL, G.A. Soil heating by solarization inside plastic greenhouse in Santa Maria, Rio Grande do Sul, Brazil. Agricultural and Forest Meteorology, Amsterdam, v.82, n.1, p. 73-82, 1996.

STRECK, N.A.; HELDWEIN, A.B.; SCHNEIDER, F.M.; BURIOL, G.A. Effect of colored plastic mulches on soil and air temperature inside a plastic greenhouse. Revista Brasileira de Agrometeorologia, Santa Maria, v.5, n.2, p. 165-170, 1997.

SUN, H.; SHAO, L.; LIU, X.; MIAO, W.; CHEN, S.; ZHANG, X. Determination of water consumption and the water-saving potential of three mulching methods in a jujube orchard. European Journal of Agronomy, Amsterdam, v.43, p. 87-95, 2012.

VAN DONK, S.J.; MARTIN, D.L.; IRMAK, S.; MELVIN, S.R.; PETERSEN, J.L.; DAVISON, D.R. Crop residue cover effects on evaporation, soil water content, and yield of deficit-irrigated corn in west-central Nebraska. Transactions of the ASABE, Saint Joseph, v.56, p. 1787-1797, 2010.

ZRIBI, W.; FACI, J.M.; ARAGUÉS, R. Efectos del acolchado sobre la humedad, temperatura, estructura y salinidad de suelos agrícolas. ITEA, Zaragoza, v.107, p. 148-162, 2011.

ZUCARELI, C.; CAVARIANI, C.; SBRUSSI, C.A.G.; NAKAWA, J. Teste de deterioração controlada na avaliação do vigor de sementes de milho. Revista Brasileira de Sementes, Viçosa, MG, v.33, p.732-742, 2011. 